\title{
Personal therapy in psychiatric training
}

Although personal psychotherapy has become less popular among psychiatrists in training (Weintraub et al, 1999), it remains mandatory for UK specialist registrars training in psychodynamic and psychoanalytic psychotherapy (PPP). As a training requirement, this can appear anomolous. Within psychiatry, PPP specialist registrars have been joined by small, but growing, numbers of trainees specialising in cognitive-behavioural therapy who are not obliged to have this experience. Post-Calman streamlining of training across medical specialities does not favour components that are relatively expensive and take time away from a training schedule that is very short, yet very full.

Arguments about the value of personal therapy for specialist registrars may also apply to other psychiatrists. Three questions will be considered: why should personal therapy be a core requirement for psychotherapy trainees; what is the most appropriate form for it to take; and what implications do answers to these questions have for other psychiatrists?

\section{Rationales}

Rationales for personal therapy in training are often expressed in technical language (e.g. to understand countertransference). At their simplest, they come down to three kinds of argument - professional, educational and personal. Separated here for ease of analysis, these inevitably reinforce each other.

\section{Professional need}

Personal therapy is an established training requirement, alongside supervised practice and theoretical teaching, for all non-psychiatrists registered with the UK Council for Psychotherapy except for behavioural-cognitive; family-systemic; and experimental constructivist therapists. Consultants in psychotherapy have a dual professional role - as psychotherapists and psychiatrists. Their professional training should, therefore, meet standards upheld by both groups, including personal therapy when this would be expected of non-psychiatrists undergoing comparable training.

The argument appears a strong one - it parallels the requirement for maxillo-facial surgeons to train in clinical dentistry to standards no different from those applying to non-medical dentists. In the case of medical psychotherapy, the College (at least currently) retains effective control of standards in these psychiatrists' psychotherapy training.

Professional requirements, however widely observed, should be justified. Ideally, they will maintain core professional standards such as the quality of care patients receive or personal conduct. A recent review attempted to relate clinical outcomes to therapists'exposure to personal therapy, but, like its predecessors, found no clear association (Macran \& Shapiro, 1998). This is not surprising, given a research base that is unable to demonstrate, as yet, that psychotherapeutic training significantly improves clinical outcomes. As for professional ethics, studies of therapist abuse indicate that previous personal therapy appears not to prevent (or predispose to) boundary violations when these occur (Gabbard, 1997).

Despite this, a third traditional justification for professionally sanctioned procedures - that they are necessary to maintain public confidence - is also relatively easy to test here. Patients' groups do seem to prefer that psychotherapists, with whom they expect to have an unusually intimate working relationship, have received psychotherapy themselves.

\section{Educational benefits}

According to the educational argument, personal therapy confers knowledge, aptitudes and/or skills thought necessary for competent clinical performance. Freud (1937) had thought a psychoanalyst's personal analysis was the only vehicle by which essential techniques, such as working with resistance and transference, could be learned. A strong educational case would identify learning during personal therapy that was unlikely to occur in teaching or supervised practice alone. Objectives here need to be defined for claims to be testable through comparative research.

Although Macran \& Shapiro's (1998) review cites four possible attainments (insight into personal conflicts and behaviours; greater sensitivity to patients'experiences; learning of effective procedures; and personal belief in the efficacy of therapy), it only cites evidence in support of the second, with respect to development of empathy. Weintraub etal's(1999) US survey confirms increased beliefin efficacy to be a common outcome of personal therapy also. Macaskill (1988) suggested that any differences in personal awareness and practical skill conferred by personal therapy are likely to be evident only intermittently, at times when particularly challenging situations put therapists under pressure to act immediately in clinically questionable ways.

This indicates one way therapy may contribute to trainees' procedural knowledge, as distinct from the declarative knowledge that formal teaching confers. Other clinically important aptitudes may only be developed through the kind of close interactions that personal therapy affords. These would include the 'implicit relational learning' that appears to be crucial to some therapeutic communication (Stern et al, 1998). Depending on attunement of non-verbal responses between therapist and patient, this learning is fostered through direct experience and has no equivalent in taught verbal interventions. 
an

editorials
For the present, acceptance that personal psychotherapy contributes to specific educational objectives suggests that the form of the therapy can be tailored according to those objectives, instead of necessarily imitating in all particulars the therapy the practitioner will perform after completing training. In practice, training therapies tend to be more protracted and frequent than most of the treatments the recipients subsequently offer. It may not be realistic to expect all educational objectives to be met within a single personal therapeutic experience during training

\section{Personal resilience}

The personal case is that, even with a licence to practise and a good deal of study, it is unlikely that psychiatrists will function well when undertaking psychotherapeutic work without a prior personal therapeutic experience. The therapy enables because it is personal and because it is therapeutic. It helps therapists to think and to feel in ways essential to performing effectively, protecting them from being overcome by anxiety or other emotional demands of their work. Crudely stated, this argument would be supported if undertaking comparable work without prior therapy carried a higher risk of illness and 'burn-out'. It is also the argument to which evidence from professional surveys, the kind most frequently collected concerning personal therapy, has the greatest contribution to make.

Reports by trained therapists generally support the notion that personal therapy protects (Beutler et al, 1994). An important caveat comes from surveys of trainees, indicating some professionally destabilising effects. These include personal and domestic distress (Macaskill \& Macaskill, 1992) and interference with concurrent clinical work (Glass, 1986), particularly in the early stages of training. To minimise this disruption, it may be reasonable to defer other elements of training until personal therapy is already well underway. This is common practice for other psychotherapy trainees. Psychiatrists who are candidates for PPP training may, therefore, reasonably be required to have had some prior personal therapeutic experience.

Practitioner surveys of the experience of personal therapy have not always differentiated between previous therapy undertaken during formal training and continuing therapy begun subsequently. The contribution of the latter to personal effectiveness is relevant to all psychiatrists as well as specialists in psychotherapy. More information on the specific benefits of receiving continuing therapy beyond or independently of formal training seems required. If earlier observations about the value of therapy in training are valid, the circumstances in which continuing therapy could be a legitimate component of continuing professional development (CPD) ought to be clarified. Freud (1937; p. 249) had observed that, in order to maintain his or her sensitivity, every analyst should "at intervals of five years or so - submit himself to analysis once more". It is interesting that the General Medical Council should alight on a similar interval for future revalidation of all registered specialists.

\section{Conclusions}

The relevance of the professional, educational and personal rationales for personal therapy will vary for different groups of psychiatrists. For trainees in PPP, the professional rationale seems compelling. The educational rationale can apply to all trainee psychotherapists, whatever their preferred model. Considerable flexibility in the form therapeutic experience takes may be necessary to meet educational objectives. The personal rationale is not only relevant to trainees, but many other psychiatrists. It might apply to personal therapy undertaken at any stage of a psychiatrist's career. As the personal and educational merits of continuing therapy are not necessarily easy to separate, its place in CPD needs to be reviewed.

\section{References}

BEUTLER, L.E., MACHADO, P. P. P., NEUFELDT, S. A. (1994)

Therapist variables. In Handbook of Psychotherapy and Behaviour Change (eds A. E. Bergin \& S. L. Garfield) pp. 229-269. NewYork: JohnWiley.

FREUD, S. (1937) Analysis terminable and interminable. Reprinted (19531974) in the Standard Edition of the Complete Psychological Works of Sigmund Freud (trans. and ed.

J. Strachey), vol. 23, pp. 211-253. London: Hogarth Press.

GABBARD, G. O. (1997) Lessons to be learned from the study of sexual boundary violations. Australian and New Zealand Journal of Psychiatry, 31, 321-327.

GLASS, J. (1986) Personal therapy and the student therapist. Canadian Journal of Psychiatry, 31, 304-311.

MACRAN, S. \& SHAPIRO, D. A. (1998) The role of personal therapy for

therapists: a review. British Journal of Medical Psychology, 71, 13-26.

MACASKILL, N. D. (1988) Personal therapy in the training of the psychotherapist: is it effective? British Journal of Medical Psychology, 4. 219-226.

— \& MACASKILL, A. (1992) Psychotherapists-in-training evaluate their personal therapy: results of a UK survey. British Journal of Psychotherapy, 9, 133-138.

STERN, D. N., SANDER, L.W., NAHUM J. P., et al (1998) Non-interpretation mechanisms in psychoanalytic therapy - the 'something more' than interpretation. International Journal of Psychoanalysis, 79, 903-921.

WEINTRAUB, D., DIXON, L. KOHHEPP, E., et al (1999) Residents in personal psychotherapy: a longitudina and cross-sectional perspective. Academic Psychiatry, 23, 14-19.

Chris Mace Senior Lecturer in Psychotherapy, University of Warwick and Consultant Psychotherapist, South Warwickshire Combined Care NHS Trust 